\title{
CONCURSO DE DIREITO ADMINISTRATIVO
}

\section{Municipalização de serviços públicos}

(Ponto sorteado)

\section{Mario Masagão}

A expressão "municipalização de serviços públicos" tem em direito administrativo, e em ciência da administração, dois sentidos bem distintos.

No primeiro, é referente à atribuição, aos municípios, de serviços que, para esse efeito, são retirados da esfera de ação do Estado. Sob este aspecto, a municipalização é atinente ao problema da centralização' ou descentralização administrativa.

No segundo sentido, a expressão significa atribuição aos municípios, com carater de monopólio, de serviços que comumente são executados por particulares.

Trataremos, a seguir, dos 'principais problemas que surgem no assunto, cuidando primeiramente da municipalização comio elemento do processo descentralizador, e, em seguida, da sua feição relativa à criação de monopólios industriais. Esta última é sem dúvida a face de mais interesse da matéria, no atual momento.

Na distribuição das funções entre o Estado e o município, uma regra fundamental existe, acolhida em todas as legislações: ao município sòmente devem competir funções relativas aos interesses locais. Sempre que se trate 
de tutelar înteresses gerais, isto é, iexcedentes das circunscrições territoriais dos' municípios, a função deve caber ao Estado.

À vista dessa regra, fica imediatamente colocada fóra do âmbito da ação municipal toda a atividade relativa à tutela do direito. Não há nem pode haver interesse geral maior 'que o da tutela do direito, em qualquer de suas faces. Assim, a declaração do direito, a manutenção da ordem interna, a defesa da nação contra o inimigo externo, e a distribuição de justiça, escapam inteiramente à esfera ide ação municipal.

Qual, porém, a atividade que deve competir ao município, 'fóra do campo da tutela do direito? Que parcelas lhe cabem, na ativildade puramente social, isto é, relativa ao bem estar, cultura e progresso?

Quatro são 'as principais doutrinas surgidas no assunto.

A primeira, defendida na Itália pelo senador Fusinato, é a de que não existem limites teóricos à ação social do município, senão aqueles que são reconhecidos como atinentes à própria atividade social do Estaido. Só as circunstâncias de momento, devidamente aprecialdas, podem ditar ao legislador critérios, sem dúvida eminentemente empíricos, para que dilate ou restrinja as funções municipais.

A segunda teoria, patrocinada pelo eminente Borsi, que lhe dedica largo desienvolvimento na monografia com que ilustrou o segundo volume do Tratado de Orlando, é a de que o critério da utilidade domina soberanamente a matéria. A ação social do município será sempre lícita, se convier à utilidade dos munícipes.

A terceira teoria, propugnada por Mezzanotte, em seu livro intitulado "Il comune' italiano", quasi que se confunde com as duas primeiras, quando profundamente analisada. Pretende Mezzanotre que, na atribuição de funções aos municípios, deve o legislador estadual atender a dois critérios: o de que a atividade de que se cuida aproveite à generalidade dos municipes, e o de que, ao mesmo tempo. não ultrapasse os limites da circunscrição territorial. 
Finalmente, a última teoria, exposta e defendilda por Magnani, em sua preciosa monografia sôbre a administração provincial, aponta como único critério atendivel o da delegação. Sempre que a lei do Estado atribua ao município determinada função, esta fica justificada pelo simples fáto da delegação, que a atribuição encerra.

A teoria da delegação ganha cada dia terreno, no campo da doutrina. E o próprio Borsi, em recente artigo publicado na "Rivista di Diritto Pubblico", em flascículo cujo número não nos acode no momento à memória, declara que, hoje, tơdas as funções municipaiis, na Itália, só se justificam pela delegação do Estado.

A vitória desta teoria vem, como é evidente, destronar a antiga doutrina do mínimo irredutivel de atribuições do município, a qual começou a perder terreno desde o monumental trabialho de GNEIsT sôbre as comunas inglesas. Aí se demonstrou, de maneira convincente, que não passa de um míto o conjunto de poderes havidos até então como pertencentes, por direito próprio, aos municípios ingleses.

No direito positivo brasileiro, não pode ser aceita, em todas as suas consequências, a teoria da delegação. Há texto expresso ide lei, em 'contrário. E' o do art. 68 da Constituição Federal de 24 de fevereiro, que dispoz: "Os Estados organizar-se-ão 'de forma a que fique assegurada a autonomia dos municípios, em tudo iquanto respeite ao seu peculiar interesse".

Embora defeituoso na técnica, pois que alude a autonomia ao mesmo tempo que aos interesses peculiares dos municípios, (quan'do é certo que a regra de autonomia, atinente à constituição dos órgãos diretivos, nada tem de comum com a 'distribuição de funções), - é contuido inegável que o art. 68 da Constituição fixơ para os municípios um mínimo irrédutivel de atribuições, colocaldo fóra da dependência delegativa das assembléias estaduais.

Quais serão, entretanto, os limites desse mínimo irredutivel? 
Parece impossivel uma predeterminação teórica, nesise terreno. Em direito constituido, há apenas que atender às atribuições municipais fixadas nas leis do Estado. $O$ legislador estadoal é, assim, o intérprete forçado do art. 68 da Constituição federal, e exerce essa interpretação cada vez que atribue aos municípios competências funcionais.

$\mathrm{Na}$ impossibilidade de examinar, nesta prova, as legislações de todos os Estados brasileiros, diremos apenas que, no Estado de São Paulo, as principais funções atribuidas aos municípios são: fomentar lo desenvolvimento da lavoura, das artes e das indústrias, por meio de medidas e auxílios gerais, que não envolvam privilégios; criar agências de imigração e alojamentos para imigrantes, promovendo a introdução e colocação deles no município; criar escolas de ensino primário e profissional; auxiliar estabelecimentos particulares de ensino; prover ao alinhamento, limpeza, calçamento, reparação e conservação de ruas, praças, e mais logradouros públicos; fazer aferição de pesos e medidas; regulamentar matadouros, talhos, feiras, mercados; fiscalizar indústrias, principalmente as de inflamáveis; füscalizar o comércio de gêneros alimentícios; providenciar o abastecimento de água, e o estabelecimento de esgotos, e de iluminaçãol; regulamentar jogos, espetáculos e divertimentos públicos; socorrer indigentes; estabelecer hospitais, asilos, etc., e cuidar da higiene do município, mediante providências que não contrariem als leis do Estado.

As atribuições municipais no nosso Estado constam miudamente da lei $n .^{\circ} 1.038$, de 1906 , e de outras que a mo:dificaram, parecendo-nos dispensável exemplificação maior que a acima exarada.

Passemos agora a considerar a municipalização de serviços públicos no segundo sentido dessa expressão. Como dissemos, a assunto, sob este aspecto, of erece maior interesse teórico.

De tal forma considerada, a municipalização de serviços públicos pode ser definida, com Montemartini, como a produção direta, exercida pelo município, com o fim de ob- 
ter preço unitário menor que o obtido no regime de livre concorrência dos particulares.

Há duas espécies bem distintas de municipalização.

Em primeiro logar aparece a que tem em mira o simples benefício dos cidadãos, como o oferecimento, a êles, de serviços ou produtos melhores, mais baratos, e de existência segura.

Em segundo logar aparece a chamada municipalização de intúitos fiscais, destinada a suprir deficiências financeiras do município.

As justificações e as críticas que se dirigem a essas duas espécies de municipalização diferem bastante. Devemos, portanto, cuidar de uma e de outra separadamente.

Os partidários da municipalização da primeira espécie costumam aduzir em defesa de sua opinião os seguintes argumentos:

$10^{\circ}$ - A municipalização acarreta o barateamento dos produtos;

$2 .^{\circ}$ - Produz igualmente a melhoria da sua qualidade, isentando-os de defeitos que são comuns no comércio dirigido pelo espírito imoderado de lucro;

$3 .^{\circ}$ - A continuidade e regularidade do fornecimento ficam assegurados pela municipalização;

4. ${ }^{\circ}$ - $O$ serviço municipalizado e barateado põe o produto ao alcance dos menos favorecidos pela bôa fortuna, e generaliza o respectivo gozo entre todos os munícipes;

5. ${ }^{\circ}$ - O maior crédito, de que gozam as pessoas jurídicas de direito público, lhes permite a obtenção de capitais a juros mais baixos que os pagos por empresas particulares. Por outro lado, os municípios não têm que pagar dividendos nem quotas de lucros a acionistas ou sócios de qualquer espécie. Por isso mesmo, os produtos, nas indústrias municipalizadas, são obtidos por um custo menor.

6. - Em razão dos motivios anteriormente apontados, está o município em condições de pagar aos seus operários 
salário mais elevado que o comúm. O bem estar das clases proletárias, sem encarecimento do produto, é, assim, consequência da municipalizaçãio.

7. ${ }^{\circ}$ - Finalmente, os lucros da produção municipalizada vém permitir, sem sacrifício dos serviços públicos, a diminuição dos impostos. Os munícipes lucrarão, consequentemente, quer como consumidores, quer como contribuintes.

A esses argumentos respondem os adversários da municipalização com outros, e de não menor peso. Eis os principais :

$1 .^{\circ}$ - E' notória e proverbial a incapacidade das pessoas jurídicas de direito público para a produção econômica. Falta, a essas pessoas, que só podem operar por meio de funcionários, o elemento essencial do êxito nos empreendimentos industriais: o interesse pessoal dos diretores da indústria, e dos seus fiscais. Sem a móla do interesse pessoal e direto, não há direção nem fiscalização eficiente. A produção industrial do Estado e do Município será sempre mais cara e de qualidade inferior.

2. - A municipalização tem como consequência imediata o acréscimo do maior mal do Estado moderno: o aumento assustador do funcionalismo público.

3. - A ação normal do Estado e do Município já acarreta, por si mesma, grande número de pleitos em que aquelas entidades figuram como autores ou réos. Até onde será levada essa multidão de demandas, se à ação normal do município for acrescida a de produtor em grande escala?

$4 .^{\circ}$ - Se ao município se devem confiar monopólios de produção, mais proveitosa, sob o aspecto econômico, é a produção indireta, que êle consegue por meio da concessão. Nesta última, poderá êle, ao menos, reservar para si uma parte dos lucros, e contar com o numerário assim assegurado. Na produção direta, o município só conseguirá lucros a custa de uma extraordinária elevação dos preços de 
venda, o que prejudica de maneira irremediavel o mais elementar interesse dos munícipes.

A nossa opinião pessoal é absolutamente contrária à municipalização, pelos motivos que enumeramos em segundo logar, e aos quais aderimos inteiramente.

A nosso vêr, a municipalização é um mal. Só a admitimos, como remédio último, no caso da saturação em matéria tributária.

Quando os contribuintes já não puderem suportar qualquer agravação nos impostos e nas taxas, e quandio, ao mesmo tempo, circunstâncias irremovíveis impuserem a necessidade do aumento da arrecadação, será lícito ao município, como ao Estado, lançar mão da produção industrial, para equilíbrio do orçamento.

Só admitimos, consequentemente, e quando imposta por circunstâncias gravíssimas, a segunda espécie de municipalização, a que atraz aludimos: a espécie fiscal.

Examinemos agora a matéria diante do direito positivo brasileiro.

Estabelece a Constituição Federal no art. 72, § 24, que é garantido o livre exercício de qualquer profissão, moral, intelectual e industrial.

Com esse preceito, a Constituição impediu, sabiamente, a existência de qualquer monopólio, no país.

E' evidente, entretanto, que o citado texto não impede a existência de privilégios exclusivos, coisa muito diferente dos monopólios.

O característico do monopólio é arrancar do campo da atividade dos cidadãos uma parte que legitimamente nela se integra, para atribuí-la ao monopolizador. Este fica, assim, beneficiado a custa de uma injusta restrição da atividade alheia.

No privilégio exclusivo não aparece essa circunstância.

Ele beneficia as pessoras jurídicas de direito público, não mediante o cerceamento das atividades individuais, e sim em razão da própria natureza das coisas. 
Há atividades que exigem a utilização direta e imediata de bens públicos de uso comúm, tais como a superfície, o espaço aéreo e o sub-solo das ruas e praças públicas. Não é possivel conduzir a água, io gaz, a eletricidade, nem estabelecer o transporte urbano por linhas férreas, sem aquela utilização.

Essa circunstância tira, por si própria, do campo das atividades individuais, o exercício das apontadas indústrias.

Nenhum individuo, por direito próprio, pode ocupar de maneira permanente e direta bens públicos de uso comum.

A'penas a União, os Estados e os Municípios, a quem cabe na forma da lei a administração de tais bens, poderão exercer as indústrias que exijam semelhante utilização.

Eis aí os privilégios exclusivos de que gozam entre nós as pessoas jurídicas de direito público interno, sem violação do preceito constitucional do art. $72, \S 24$, pelo qual ficaram vedados os monopólios.

Mas, todios os princípios científicos, e a experiência dos povos, demonstram, a nosso vêr, a absoluta inconveniência do exercício da atividade industrial pelas pessoas jurídicas de direito público.

"O Estado é máu produtor". Eis um axioma de ciência da administração.

Mesmo em se tratando de privilégio exclusivo, consequentemente, o exercício direto da produção industrial, pela União, pelos Estados e pelos municípios, será um mal.

$O$ instituto da concessão obviará a todas as dificuldades. E a entidade que gozar do privilégio exclusivio obterá os lucros que a essa situação correspondem, optando pela forma de execução indireta do serviço.

Em conclusão, resumimos o nosso pensamento sôbre o assunto da seguinte forma:

$10^{\circ}$ - A municipalização com o intuito de beneficiar o consumidor deve ser absolutamente proscrita, porque na prática são de impossível consecução os seus desígnios. 
2. - A municipalização com intuitos fiscais é admīssivel apenas quando as circunstâncias a impuzerem como único remédio para restabelecimento de finanças precárias.

3. ${ }^{\circ}$ - As circunstâncias, acima aludidas, não podem ser determinadas a priori, e sòmente se tornam apreciáveis em cada caso, mediante aplicação dos critérios fornecidos pela Ciência das Finanças e pela Ciência da Administração.

4. ${ }^{\circ}$ - No direito positivo brasileiro, a municipalização com carater de monopólio é impedida pelo art. $72, \S 24$, da Constituição Federal.

5. - - Os serviços municipalizados em razão de privilégios exclusivos devem ser exercidos, de preferência, por intermédio de concessionários, reservando-se ao concedente uma equitativa participação nos lucros da empresa.

São Paulo, 27 de junho de 1933. 